\title{
The Interannual Variation of Intraseasonal Oscillation Linked with the Indian Ocean Dipole Mode
}

\author{
Masaki Ito and Takehiko Satomura \\ Graduate School of Science, Kyoto University, Kyoto, Japan
}

\begin{abstract}
Influence of the Indian Ocean Dipole Mode (IOD) on the interannual variation of the activity of intraseasonal oscillation (ISO) on submonthly (6-30-day) time scales during boreal fall is studied using ECMWF reanalysis data from 1958 to 2001. There is high negative correlation between the IOD and ISO activity over the southeastern Indian Ocean. The disturbances that cause this high negative correlation propagate westward slowly while maintaining a symmetric structure with respect to the equator and have the first baroclinic vertical structure. These disturbances are identified as convectively coupled equatorial Rossby waves. It is also shown that the interannual variation of ISO activity has a high correlation coefficient (0.850) with maximum negative relative vorticity anomalies at $850 \mathrm{hPa}$ produced by cyclonic disturbances over the southeastern Indian Ocean, while it has a low coefficient (0.119) with the number of cyclonic disturbances. It is concluded that whether the equatorial Rossby waves produce strong cyclonic disturbances is a key factor determining the interannual variation of ISO activity over the southeastern Indian Ocean. The reason strong cyclonic disturbances are produced and their relation with the IOD are discussed in this paper.
\end{abstract}

\section{Introduction}

It is well known that the tropical and subtropical climates are profoundly affected by atmospheric intraseasonal oscillation (ISO), and that the ISO activity changes greatly every year. Since the locality of generation and seasonal variation of ISO are closely related with air-sea interaction (e.g., Kemball-Cook and Wang 2001), many studies link the interannual variation of ISO with that of sea surface temperature (SST). For example, Hendon et al. (1999) analyzed the relation between the interannual variation of the activity of the Madden-Julian oscillation (MJO; Madden and Julian 1972) during boreal winter and the variation of SST anomaly caused by El Niño-Southern Oscillation (ENSO). They showed that, during El Niño, the large activity region of the MJO shifts east of the date line from the equatorial Indian or western Pacific Oceans. Additionally, Bergman et al. (2001) showed that the interannual variation of MJO activity during boreal winter is highly correlated with SST anomalies during boreal fall in the western Pacific, and that the impacts of SST variation on ISO activity are not always contemporary.

In the tropical Indian Ocean, the interannual variation of SST strongly depends on the season. The anomaly pattern of SST sometimes exhibits a zonal dipolelike structure, which is called the Indian Ocean

Corresponding author and present affiliation: Masaki Ito, Forecast Department, Japan Meteorological Agency, 1-3-4 Otemachi, Chiyoda, Tokyo 100-8122, Japan. E-mail: m itoh@ met.kishou.go.jp. (C2009, the Meteorological Society of Japan.
Dipole Mode (IOD; Saji et al. 1999). The IOD is pronounced during boreal fall and affects the climate in the Indian Ocean region by changing low-level circulation and distribution of humidity (e.g., Webster et al. 1999; Saji et al. 1999). As a measure of IOD, Saji et al. (1999) defined the Dipole Mode Index (DMI) as the difference of the averaged SST anomalies between the western $\left(10^{\circ}\right.$ $\left.\mathrm{S}-10^{\circ} \mathrm{N}, 50^{\circ} \mathrm{E}-70^{\circ} \mathrm{E}\right)$ and eastern $\left(10^{\circ} \mathrm{S}-0^{\circ} \mathrm{S}, 90^{\circ} \mathrm{E}-110^{\circ} \mathrm{E}\right)$ Indian Ocean.

The submonthly-scale ISO activity and its interannual variation are particulary large in the tropical Indian Ocean (e.g., Kemball-Cook and Wang 2001). Shinoda and Han (2005) analyzed the interannual variation of the ISO activity in the tropical Indian ocean during boreal fall and its relation with the IOD. They showed that 6-30-day ISO activity has a high negative correlation with the IOD, while 30-90-day ISO activity has a lower correlation. They also showed that convectively coupled submonthly-scale cyclonic circulations are often generated and propagate southwestward in the Indian Ocean in negative IOD years. However, the structure and source of these cyclonic circulations were not discussed. Also, it is still unclear whether these cyclonic circulations are the only factor that produce the interannual variation in ISO activity over the region.

This paper investigates the cause of the interannual variation of ISO over the southeastern Indian Ocean under the influence of the IOD. We focus on 6-30-day time scales during boreal fall and use an ECMWF reanalysis data set. The structure of convectively coupled cyclonic circulations reported by Shinoda and Han (2005) and their relation with equatorial waves are also examined.

\section{Data and method}

The period analyzed is 1958 to 2001 boreal fall (September-October-November (SON)). The data are from the ECMWF 40-yr reanalysis data set (ERA-40; Uppala 2002). Daily data are constructed by averaging instantaneous values at 00 and 12 UTC for each day. The horizontal resolution is $2.5^{\circ}$ in longitude and latitude. We use 13 vertical pressure levels from 1000 to $100 \mathrm{hPa}$. The atmospheric components we used are geopotential height $(\phi)$, zonal wind $(u)$, meridional wind $(v)$, vertical p-velocity $(\omega)$, relative vorticity $(\zeta)$, divergence (DIV), and temperature $(T)$. We use the monthly mean Extended Reconstructed Sea Surface Temperature v2 (ERSST; Smith and Reynolds 2004) from 1958 to 2001. As a proxy for convective cloud activity, daily mean outgoing longwave radiation (OLR) data produced by NOAA (Liebmann and Smith 1996) are used from 1979 to 2001. The horizontal resolution of the OLR is $2.5^{\circ}$, and that of SST is $2^{\circ}$ in longitude and latitude. After removing the annual cycle from daily data, the reanalysis data and OLR are filtered into 6-30-day segments using a Lanczos filter (Duchon 1979). Hereafter, characters with a prime (e.g., $\phi^{\prime}$ ) denote 6-30-day filtered time series. Additionally, in order to identify cyclonic disturbances, the Cyclone Best Track from the Joint 
(a)

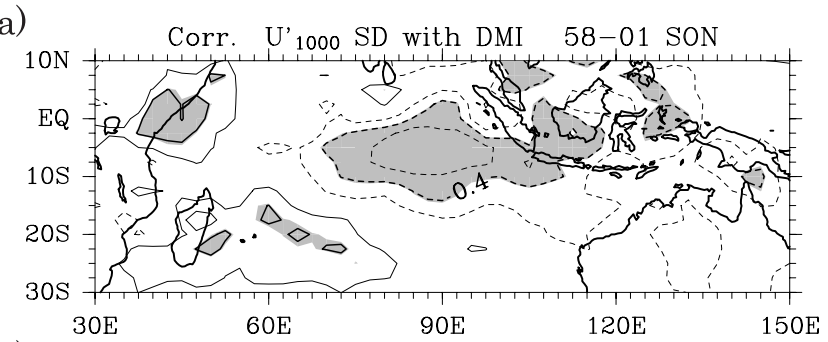

(b)

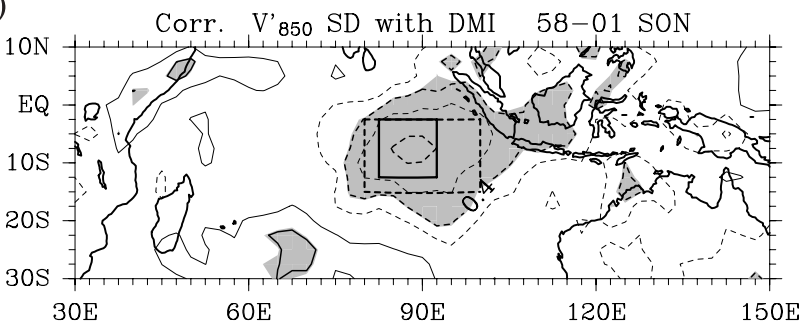

Fig. 1. Correlation coefficient of (a) $u_{1000}^{\prime}$ and (b) $v_{850}^{\prime}$ standard deviation during SON with DMI for 19582001. The contour interval is 0.2 with negative contours dashed, and the zero contour has been omitted. Shadings are locally statistically significant at the $99 \%$ level. (b) The solid-line box shows ISES and the dashed-line box shows ISE.

Typhoon Warning Center (JTWC) is used from 1980 to 2001.

As a measure of IOD, DMI averaged over SON for each year is used. Here, we define the SST anomaly in DMI as the difference from the monthly climatology. We define the years when the DMI is larger than $+0.5 \mathrm{~K}$ (smaller than $-0.5 \mathrm{~K}$ ) as positive (negative) IOD years in this paper.

The index of ISO activity is defined by the standard deviation of $v^{\prime}$ at $850 \mathrm{hPa}\left(v_{850}^{\prime}\right)$ during SON in this study, although Shinoda and Han (2005) used that of $u_{1000}^{\prime}$ as the index. The reason to use $v_{850}^{\prime}$ is as follows. Figure 1 shows the correlation coefficient of (a) $u_{1000}^{\prime}$ and (b) $v_{850}^{\prime}$ standard deviation during SON with DMI for 19582001 . As shown, $v_{850}^{\prime}$ has a much higher negative correlation coefficient over the southeastern Indian Ocean than $u_{1000}^{\prime}$. In addition, Fig. 2 shows the interannual variation of the standard deviation of OLR' during SON $\left(\sigma_{\text {OLR }}\right)$, and the averaged $\sigma_{\text {oLR }}$ between 1979 and $2001\left(\bar{\sigma}_{\text {OLR }}\right)$. Note that the maximum coefficient region of $v_{850}^{\prime}$ is nearly coincident with the region where the interannual variation of $\sigma_{\text {OLR }}$ is large. Since the variation of OLR is closely related with the precipitation activity, the index based on $v_{850}^{\prime}$ is more appropriate for describing meteorological variation accompanying precipitation.

\section{Results}

As indicated in Fig. 1, the negative correlation coefficient of 6-30-day ISO activity during SON with DMI is particularly high over the southeastern Indian Ocean. To investigate the structure of disturbances that produce this high correlation in this region, lag-correlation analysis is conducted. First, we set a region extending $10^{\circ}$ in longitude and latitude (ISES; $12.5^{\circ} \mathrm{S}-2.5^{\circ} \mathrm{S}, 82.5^{\circ}$ $\mathrm{E}-92.5^{\circ} \mathrm{E}$, shown by solid-line in Fig. 1b), and then $\phi^{\prime}$, OLR', $u^{\prime}, v^{\prime}, \omega^{\prime}, \mathrm{DIV}^{\prime}$, and $T^{\prime}$ at each grid are regressed onto $v_{850}^{\prime}$ averaged over ISES. Day 0 indicates the contemporaneous relation when the north wind is maximum in ISES.

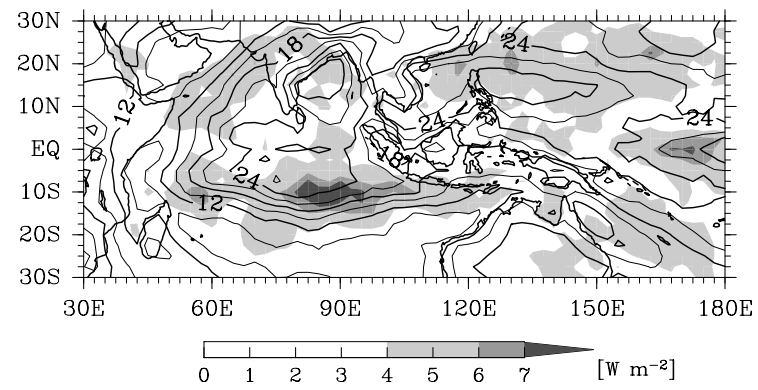

Fig. 2. Contours indicate $\bar{\sigma}_{\mathrm{OLR}}$, and shadings indicate the interannual variation of $\sigma_{\text {OLR }}$ from 1979 to 2001 . The contour interval is $4 \mathrm{~W} \mathrm{~m}^{-2}$. Note that both $\bar{\sigma}_{\text {OLR }}$ and the interannual variation of $\sigma_{\text {OLR }}$ are large over the southeastern Indian Ocean.
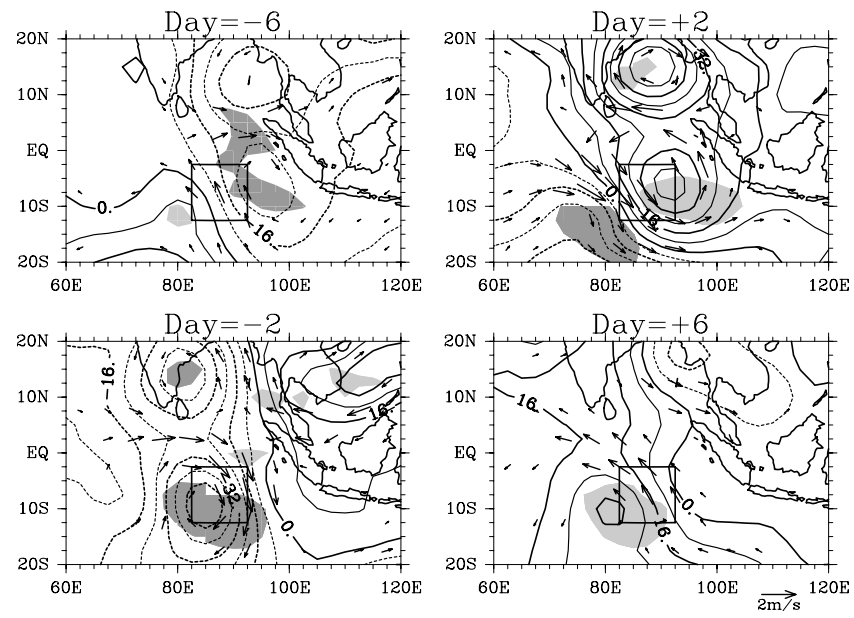

Fig. 3. Contours, shadings, and arrows indicate $\phi_{850}^{\prime}$, $\mathrm{OLR}^{\prime}$, and $\left(u_{85}^{\prime}, v_{850}^{\prime}\right)$, respectively, from day -6 (upperleft) to +6 (lowerright) every four days. Values are regressed onto $v_{850}^{\prime}$ averaged over ISES, and day 0 is when the north wind is maximum in ISES. The contour interval is $8 \mathrm{~m}^{2} \mathrm{~s}^{-2}$ with negative contours dashed. Dark and light shadings denote OLR' less than $-8 \mathrm{~W} \mathrm{~m}^{-2}$ and larger than $8 \mathrm{~W} \mathrm{~m}^{-2}$, respectively. Arrows and shadings are locally statistically significant at the 99\% level. The solid-line box shows ISES.

Figure 3 shows the regressed fields at $850 \mathrm{hPa}$ from day -6 to +6 every four days. From day -6 to -2 , there is a pair of cyclonic circulations that is symmetric with respect to the equator, and it propagates westward (and poleward) slowly. Then, from day +2 to +6 , a pair of anticyclonic circulations with symmetric structure also propagates westward slowly. This symmetric structure is similar to the first meridional $(n=1)$ equatorial Rossby wave (ER wave). The pair of cyclonic signals is located at about $10^{\circ} \mathrm{S}$ and $14^{\circ} \mathrm{N}$ at day -2 . OLR' also propagates westward and is nearly in phase with the height anomaly, which indicates that this disturbance is convectively coupled (Wheeler et al. 2000). In the northern hemisphere, the amplitude of OLR' is relatively small compared to that in the southern hemisphere.

Figure 4 shows the time-longitude cross section of regressed $\phi^{\prime}$ and DIV' at $850 \mathrm{hPa}$. The zonal phase speed and the typical period are estimated to be around $-4 \mathrm{~m}$ $\mathrm{s}^{-1}$ and 12 days, respectively. Using the shallow water equatorial wave equation with no basic flow (Matsuno 


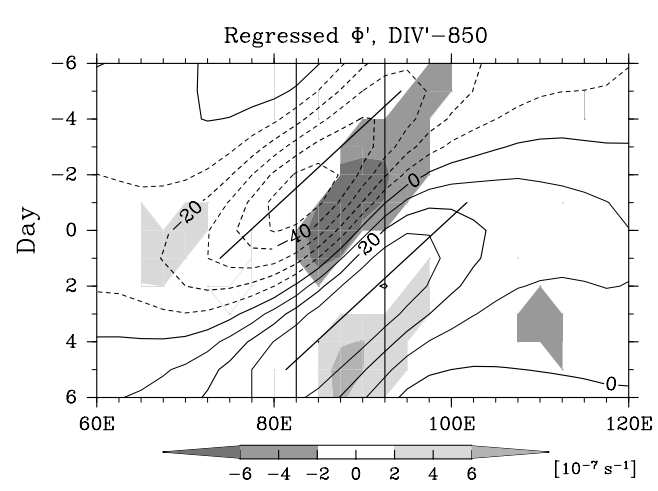

Fig. 4. Time-longitude cross section of regressed $\phi_{850}^{\prime}$ (contours) and DIV ${ }_{850}^{\prime}$ (shadings) averaged between $10^{\circ} \mathrm{S}$ and $7.5^{\circ} \mathrm{S}$. The contour interval is $10 \mathrm{~m}^{2} \mathrm{~s}^{-2}$, with negative contours dashed. Solid lines indicate westward moving speed of $4 \mathrm{~m} \mathrm{~s}^{-1}$. Shadings are locally statistically significant at the $99 \%$ level.

1966), the equivalent depth is calculated as approximately $40 \mathrm{~m}$. The Rossby radius of deformation is about $8.5^{\circ}$, and this calculated scale is slightly smaller than the scale expected from Fig. 3. The phase of DIV' lags that of $\phi^{\prime}$, and is shifted somewhat westward compared to the inviscid theoretical shallow water structure (see Matsuno 1966). Xie and Wang (1996) numerically showed that diabatic heating and basic flow vertical shear can amplify ER waves. The phase of divergence of unstable ER waves shifts westward compared to that of free waves. This phase shift becomes more evident in easterly vertical shears. Since the vertical shear is easterly over the equatorial Indian Ocean during SON (not shown), the horizontal characteristics of the present wave coincide with those of unstable ER waves.

Figure 5 shows the longitude-height cross section of regressed fields averaged between $10^{\circ} \mathrm{S}$ and $7.5^{\circ} \mathrm{S}$ at day -2 and +2 . Focusing on $\phi^{\prime}$, the first baroclinic structure with a node at $300-400 \mathrm{hPa}$ is evident. The maximum upward (downward) motion slightly lags behind the low (high) pressure in the lower level, and corresponds to the phase of lower convergence (divergence) (Fig. 4). This upward motion would reinforce the unstable wave by causing condensation heating. The anomalies of temperature become maximum in the middle and lower troposphere, and they satisfy hydrostatic equilibrium with $\phi^{\prime}$. These vertical structures and horizontal characteristics are well consistent with Wheeler et al. (2000). Hence, the disturbances that comprise of ISO in the southeastern Indian Ocean are identified as convectively coupled ER waves.

To investigate the relation between the number or the strength of cyclonic disturbances and ISO activity over the southeastern Indian Ocean, we track all cyclonic disturbances generated over ISE $\left(15^{\circ} \mathrm{S}-2.5^{\circ} \mathrm{S}\right.$, $80^{\circ} \mathrm{E}-100^{\circ} \mathrm{E}$, shown by dashed-line in Fig. $\left.1 \mathrm{~b}\right)$ using $\zeta_{850}^{\prime}$. To exclude fluctuations with small spatial scale, $\zeta_{850}^{\prime}$ is spatially smoothed with a spatial lowpass filter designed by Sardeshmukh and Hoskins (1984) having parameters $M=48, n_{0}=24$, and $r=1$, where $M$ is the cutoff wavenumber and corresponds to $7.5^{\circ}$ in longitude and latitude. We count only the number of cyclonic disturbances that are traceable for five days or more, and define the maximum absolute negative anomaly (MNA) by the minimum value of $\zeta_{850}^{\prime}$ in ISE for each disturbance.

On average, 5.6 cyclonic disturbances are found in every year, and the maximum (minimum) number is 9
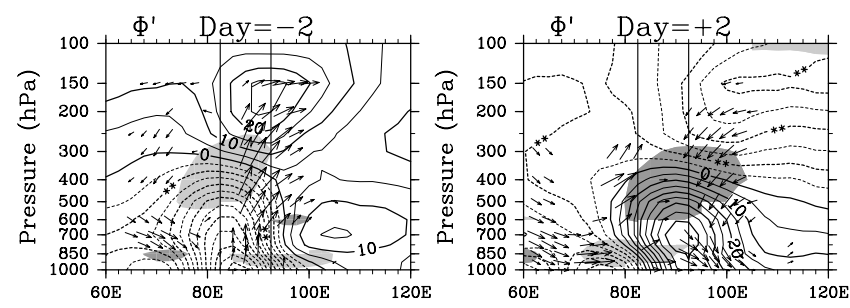

Fig. 5. Longitude-height cross section of regressed $\phi$ (contours), $T^{\prime}$ (shadings), and $\left(u^{\prime}, \omega^{\prime}\right)$ (arrows), at day -2 (left) and +2 (right). Values are averaged between $10^{\circ} \mathrm{S}$ and $7.5^{\circ} \mathrm{S}$. The contour interval is $5 \mathrm{~m}^{2} \mathrm{~s}^{-2}$, with negative contours dashed. The dark and light shadings denote $T^{\prime}$ colder than $-0.15 \mathrm{~K}$ and warmer than $0.15 \mathrm{~K}$, respectively. Arrows and shadings are locally statistically significant at the 99\% level.

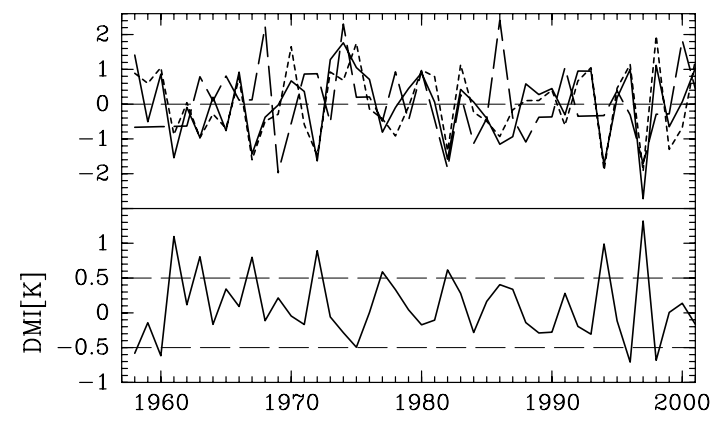

Fig. 6. Upper three time series are the ISO activity averaged over ISE (solid line), the number of cyclonic disturbances found in ISE (dashed line), and the MNA averaged for each year (dotted line) from 1958 to 2001. They are normalized by their standard deviation and the means are subtracted. Lower time series is the DMI averaged over SON. The dotted lines indicate $\pm 0.5 \mathrm{~K}$.

(3). On the other hand, for cyclonic disturbances with an MNA greater than $10^{-5} \mathrm{~s}^{-1}$, the averaged number is 1.9 , and no disturbances are found in positive IOD years, except one case in 1977 (not shown). In additon, there seems to be no relation between the number of disturbances and their intensity.

Figure 6 shows the time series of ISO activity averaged over ISE, the number of disturbances, the MNA averaged for each year, and the DMI from 1958 to 2001. While the correlation coefficient of ISO activity with the number of disturbances is low (0.119), that with mean MNA is high (0.850). Therefore, we conclude that ISO activity in ISE is hardly affected by the number of cyclonic disturbances, but is profoundly affected by their intensity.

The relation between the MNA averaged for each year and the DMI is shown in Fig. 7. They have high negative correlation coefficient $(-0.80)$. This indicates that the intensity of cyclonic disturbances is profoundly affected by the IOD, and that the disturbances tend to develop during negative IOD years.

Over 22 years (1980-2001), 26 out of 42 disturbances with an MNA greater than $10^{-5} \mathrm{~s}^{-1}$ are recorded as tropical cyclone (TC), according to the JTWC Cyclone Best Track. In particular, all disturbances with an MNA greater than $2 \times 10^{-5} \mathrm{~s}^{-1}$ (seven cases) are recorded as TC. This result is consistent with Bessafi and Wheeler (2006), who statistically showed that the vorticity anomaly in lower troposphere caused by convectively 


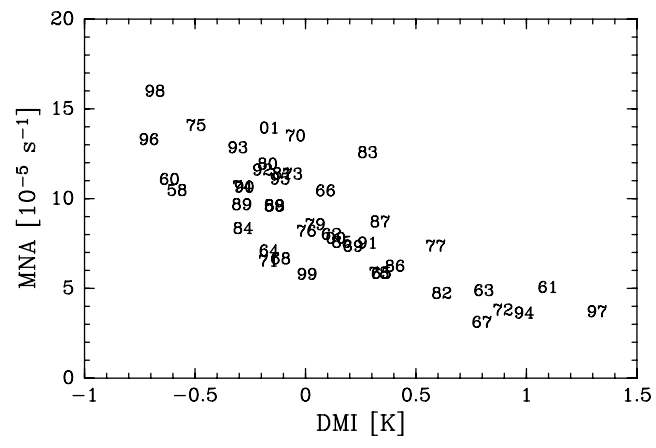

Fig. 7. Plot of the MNA $\left[\mathrm{s}^{-1}\right]$ averaged for each year versus the DMI [K] from 1958 to 2001. The number shows the last two digit of year.

coupled ER wave is an important factor in TC genesis in the south Indian Ocean.

\section{Summary and discussion}

We study the relationship between the interannual variation of 6-30-day intraseasonal oscillation (ISO) activity during boreal fall and the Indian Ocean Dipole Mode (IOD). The disturbances that produce the negative correlation between ISO activity and DMI have a symmetric structure with respect to the equator, and propagate westward (and poleward) at a phase speed of about $-4 \mathrm{~m} \mathrm{~s}^{-1}$. The typical period is about 12 days. The anomalies of $\phi^{\prime}$ and OLR' are nearly in phase in the lower troposphere, and the first baroclinic vertical structure is evident. From these characteristics, this disturbance is identified as a convectively coupled equatorial Rossby (ER) wave. The correlation coefficient of ISO activity averaged over ISE $\left(15^{\circ} \mathrm{S}-2.5^{\circ} \mathrm{S}, 80^{\circ} \mathrm{E}-100^{\circ} \mathrm{E}\right)$ with the MNA averaged for each year is high (0.850); in contrast, the coefficient with the number of cyclonic disturbances found in ISE is low (0.119). Additionally, many strong cyclonic disturbances we tracked are connected to tropical cyclones. Therefore, we conclude that the ISO activity in ISE is profoundly affected by the intensity of cyclonic disturbances. Whether ER waves produce strong cyclonic disturbances is a key factor determining interannual variation of ISO activity over the southeastern Indian Ocean.

Since the cyclonic disturbances detected by Shinoda and Han (2005) had no components in the northern hemisphere, they concluded that these disturbances weren't ER waves. They used spatially-averaged OLR' in lag-correalation analysis which is only a visualized body of meteorological phenomena and is significantly affected by thermodynamical factors. Possibly because we don't use OLR' but $v_{850}^{\prime}$, we successfully identified the disturbances as ER waves.

As described above, the MNA averaged for each year has high negative correlation coefficient with DMI $(-0.80)$. It is well known that the value of OLR, which is often used as the index of convective activity, changes greatly depending on SST (Hirst 1986), and that the SST is changed no more than $1-2^{\circ} \mathrm{C}$ by the IOD (not shown). Therefore, convective activity over the southeastern Indian Ocean is believed to change considerably between positive and negative IOD years. In addition, the easterly vertical shear of basic zonal wind and the humidity in the lower troposphere are enhanced (suppressed) during negative (positive) IOD years (not shown), and these conditions are consistent with the background that amplify (diminish) the ER waves (Xie and Wang 1996). Hence, in negative IOD years, ER waves would develop into strong cyclonic disturbances. A developed ER wave would contribute to TC genesis by producing enhanced OLR and vorticity anomaly in the lower troposphere. Therefore, the variation of wind would have negative correlation with the IOD in the southeastern Indian Ocean.

\section{Acknowledgments}

We thank ECMWF for the ERA-40 fields, NOAA for daily mean OLR data, and JTWC for the Cyclone Best Track. The GFD-DENNOU library was used to draw the figures in this paper.

\section{References}

Bergman, J. W., H. H. Hendon, and K. M. Weickmann, 2001: Intraseasonal air-sea interactions at the onset of El Niño. J. Climate, 14, 1702-1719.

Bessafi, M., and M. Wheeler, 2006: Modulation of South Indian Ocean tropical cyclones by the MaddenJulian oscillation and convectively coupled equatorial waves. Mon. Wea. Rev., 134, 638-656.

Duchon, C. E., 1979: Lanczos filtering in one and two dimensions. J. Appl. Meteor., 18, 1016-1022.

Hendon, H. H., C. Zhang, and J. D. Glick, 1999: Interannual variation of the Madden-Julian oscillation during austral summer. J. Climate, 12, 2538-2550.

Hirst, A. C., 1986: Unstable and damped equatorial modes in simple coupled ocean-atmosphere models. J. Atmos. Sci., 43, 606-630.

Kemball-Cook, S., and B. Wang, 2001: Equatorial waves and air-sea interaction in the boreal summer intraseasonal oscillation. J. Climate, 14, 2923-2942.

Liebmann, B., and C. A. Smith, 1996: Description of complete (Interpolated) outgoing longwave radiation dataset. Bull. Amer. Meteor. Soc., 77, 1275-1277.

Madden, R. A., and P. R. Julian, 1972: Description of global-scale circulation cells in the tropics with 4050 day period. J. Atmos. Sci., 29, 1109-1123.

Matsuno, T., 1966: Quasi-geostrophic motions in the equatorial area. J. Meteor. Soc. Japan, 44, 25-43.

Saji, N. H., P. N. Vinayachandran, and T. Yamagata, 1999: A dipole mode in the tropical Indian Ocean. Nature, 401, 360-363.

Sardeshmukh, P. D., and B. J. Hoskins, 1984: Spatial smoothing on the sphere. Mon. Wea. Rev., 112, $2524-2529$.

Shinoda, T., and H. Han, 2005: Influence of the Indian Ocean dipole on atmospheric subseasonal variability. J. Climate, 18, 3891-3909.

Smith, T. M., and R. W. Reynolds, 2004: Improved extended reconstruction of SST (1854-1997). J. Climate, 17, 2466-2477.

Uppala, S., 2002: ECMWF reanalysis, 1957-2001, ERA40. ERA-40 Project Report Series, 3, 1-10.

Webster, P. J., A. W. Moore, J. P. Loschnigg, and R. R. Leben, 1999: Coupled ocean-atmosphere dynamics in the Indian Ocean during 1997-98. Nature, 401, 356-360.

Wheeler, M., G. N. Kiladis, and P. J. Webster, 2000: Largescale dynamical fields associated with convectively coupled equatorial waves. J. Atmos. Sci., 57, 613 -640 .

Xie, X., and B. Wang, 1996: Low-frequency equatorial waves in vertically sheared zonal flow. Part 2: Unstable waves. J. Atmos. Sci., 53, 3589-3606.

Manuscript received 16 January 2009, accepted 8 April 2009 SOLA: http://www.jstage.jst.go.jp/browse/sola/ 